Supplement of Atmos. Chem. Phys. Discuss., 15, 27311-27355, 2015

http://www.atmos-chem-phys-discuss.net/15/27311/2015/

doi:10.5194/acpd-15-27311-2015-supplement

(C) Author(s) 2015. CC Attribution 3.0 License.

(c) (i)

\title{
How skillfully can we simulate drivers of aerosol direct climate forcing at the regional scale?
}

\section{P. Crippa et al.}

Correspondence to: P. Crippa (paola.crippa@ncl.ac.uk)

The copyright of individual parts of the supplement might differ from the CC-BY 3.0 licence. 
1 Figure S1. Empirical quantile-quantile plot of simultaneous measurements of $\mathrm{AE}$ at $500 \mathrm{~nm}$ 2 between MODIS (Terra) and AERONET (where the AEORNET station longitude (E) and 3 latitude (N) are given in the legend). As shown, the MODIS data tend to a bimodal distribution, 4 while in the AERONET observations AE is a continuous variable (or nearly so). Thus, while 5 in comparison with WRF-Chem simulations AE from AERONET is treated as a continuous 6 variable, in the majority of comparisons with MODIS a threshold of 1 is applied to identify the 7 dominance of coarse mode $(\mathrm{AE}<1)$ versus fine mode $(\mathrm{AE}>1)$.

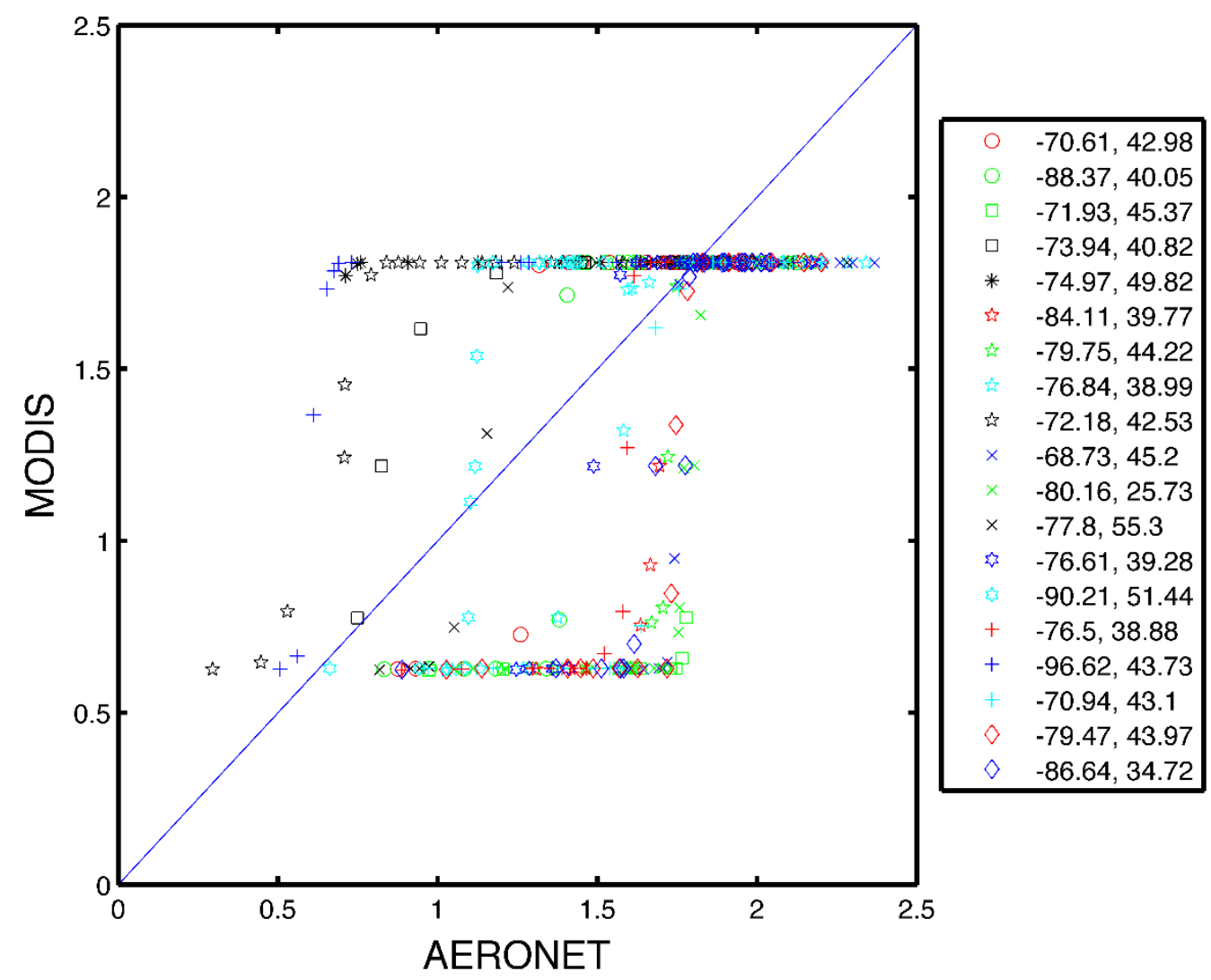


9 Figure S2. Mean fraction bias (MFB) of near-surface daily mean $\mathrm{PM}_{2.5}$ concentrations as

10 simulated by WRF-Chem and observed at EPA sites during (a) winter, (b) spring, (c) summer 11 and (d) fall. As shown, $\mathrm{PM}_{2.5}$ concentrations from WRF-Chem exhibit a positive bias (MFB > 120 ) for most sites and in most seasons, but the bias is largest over the southern states during 13 summer. Note also that the MFB in $\mathrm{PM}_{2.5}$ concentrations greatly exceeds that for either AOD 14 or AE (see Fig. 2).

(a)

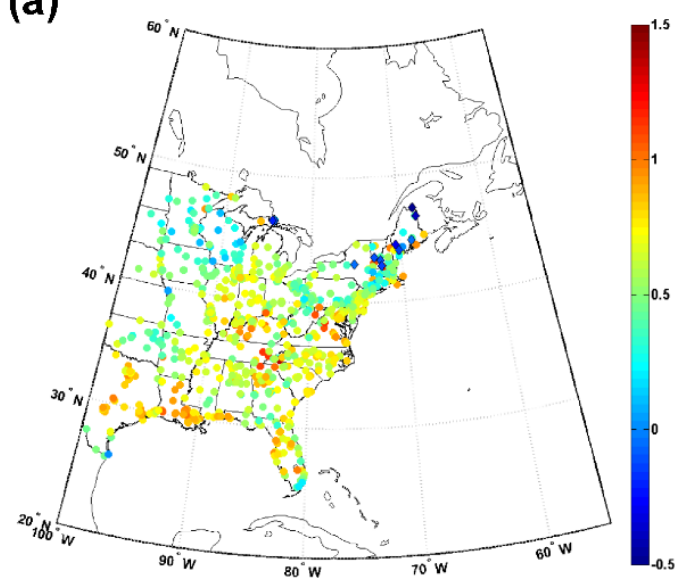

(c)

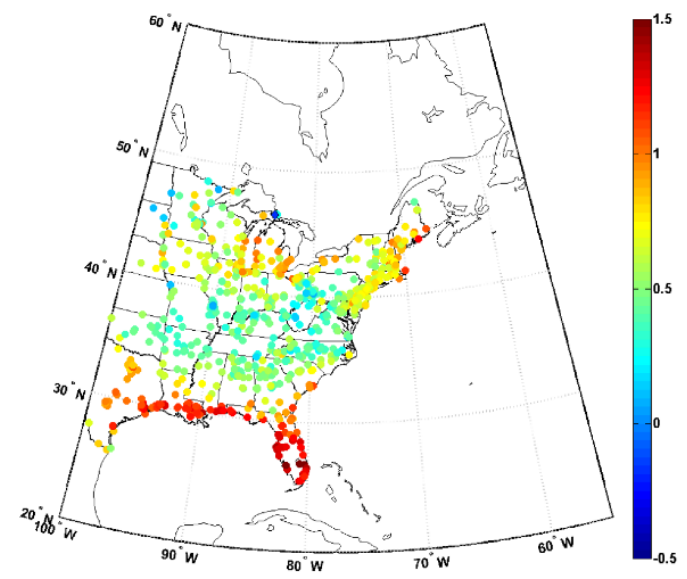

(b)

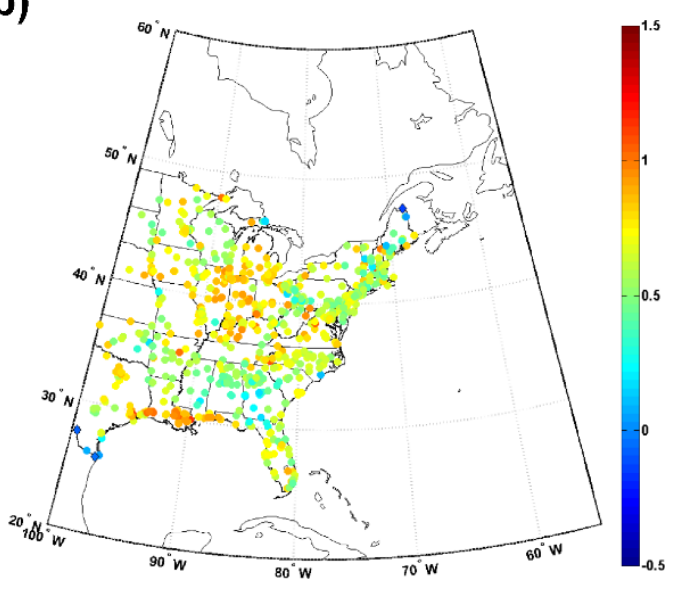

(d)

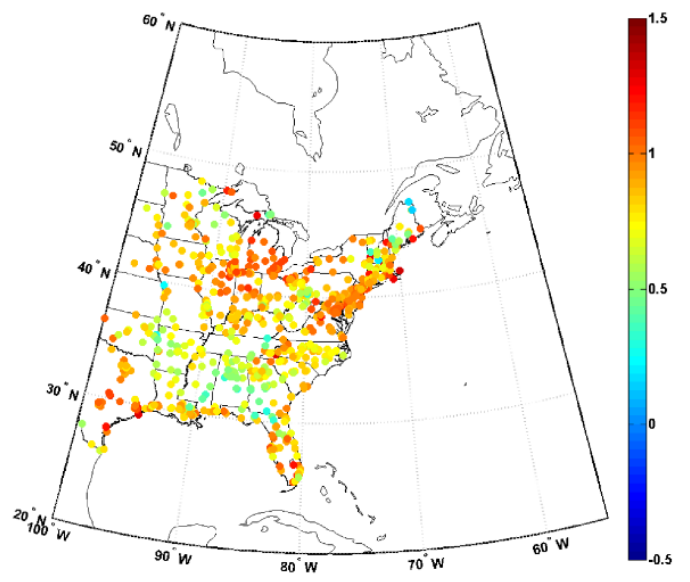


19 Figure S3. (a) Taylor diagram for monthly accumulated precipitation during 2008 as simulated 20 by WRF-Chem and in the gridded observations (Matsuura and Willmott, 2009), after applying 21 a linear interpolation to match the WRF-Chem grid. Panels (b) and (c) show the difference $22[\mathrm{~mm}]$ between observed and simulated accumulated precipitation during the month of (b) 23 September and (c) October 2008. Values larger than zero indicate the observed precipitation is 24 higher than the simulated one.

(a)

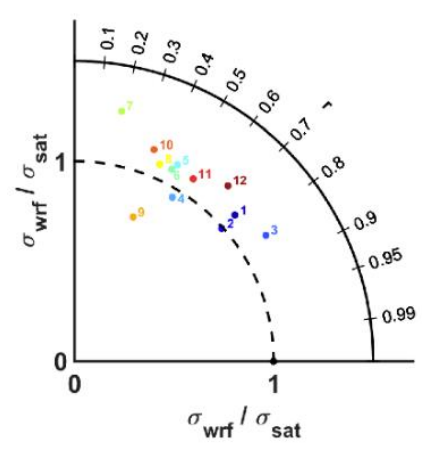

(b)

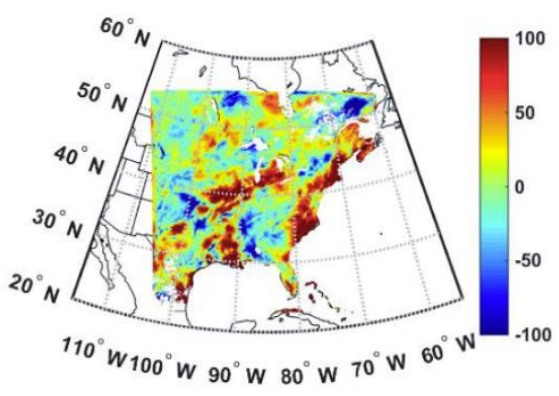

(c)

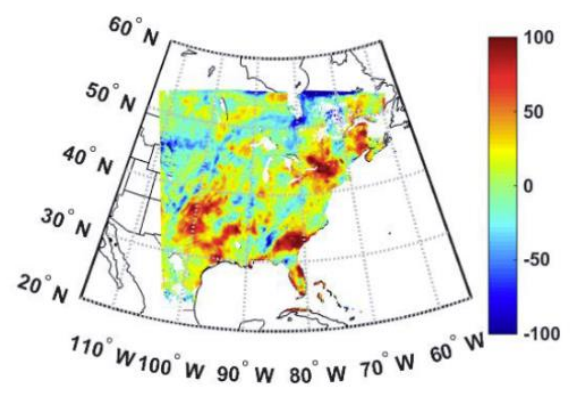


Figure S4. Spatial coherence in the identification of extreme AOD (i.e. the occurrence of AOD 31 above the $75^{\text {th }}$ percentile value) from WRF-Chem and MODIS Terra and Aqua on a monthly 32 basis. Green areas denote grid cells defined as experiencing extreme AOD in the WRF-Chem 33 simulations, blue pixels indicate extreme values as diagnosed using MODIS, while red pixels 34 indicate areas where the occurrence of extreme values is indicated by both the WRF-Chem simulations and the MODIS observations.
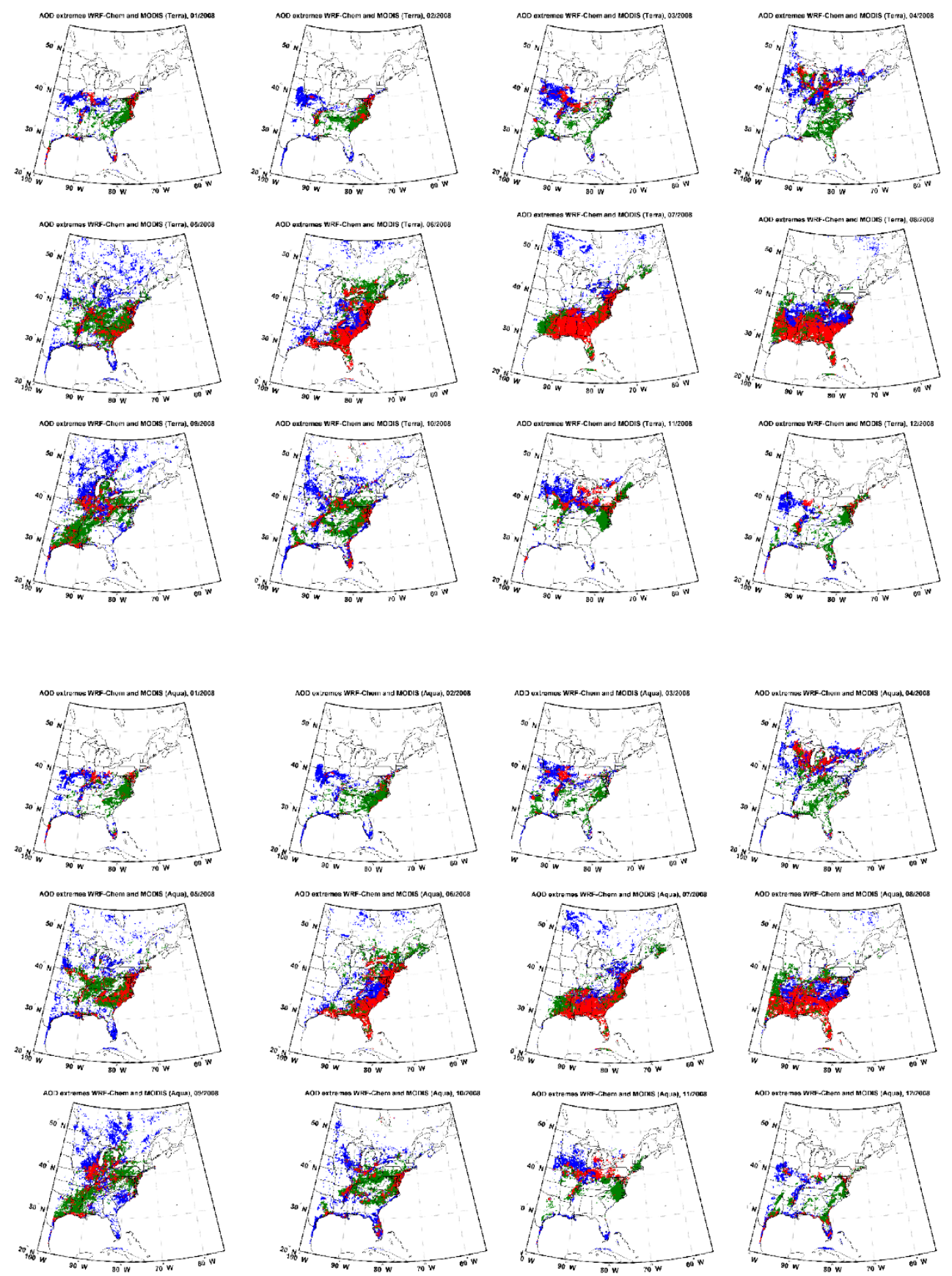
Figure S5. Fraction of near-surface monthly averaged mass concentration of nitrate versus the sum of aerosol nitrate and sulfate as simulated in the accumulation mode by WRF-Chem for each calendar month during 2008.
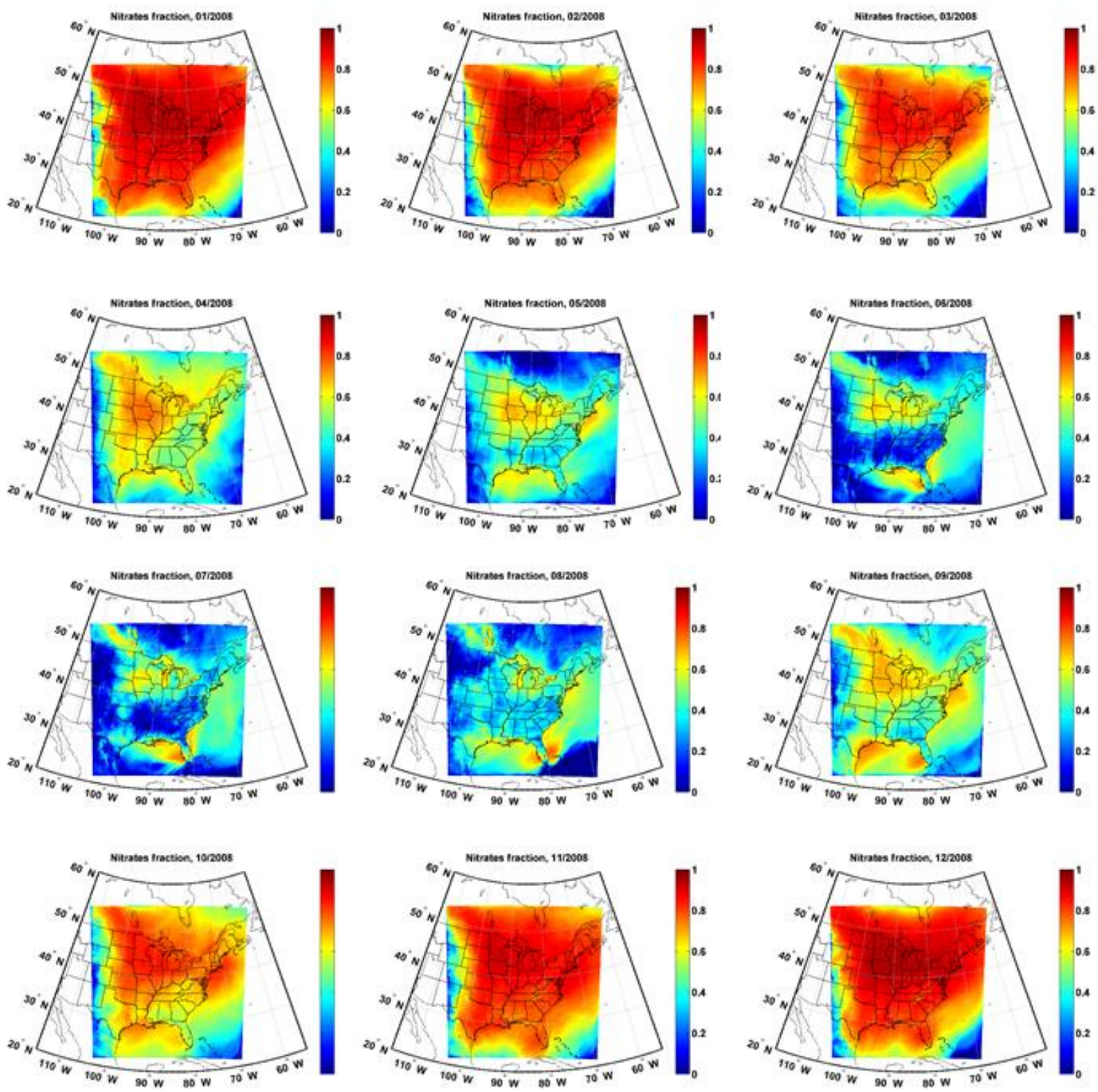